\title{
IMPACT ANALYSIS OF PHYSICAL VIOLENCE ON WOMEN
}

Paudel, Bibek ${ }^{8}$

\section{Abstract}

Women, constituting of more than 50\% of total population of the world devote their life for their family as well as children. They are the center of love and affection; the main candle of light in family as well as in nation. Despite their high value, they are being mistreated by many peoples in the world leading to the devastating social structure. The violence against women being both fatal as well as non-fatal, can bring devastation in the life as well as structure of individual and society and has taken its toll as a cancer that is spreading from within and thus is decreasing the productivity of the world and exposing whole world to vulnerability. The physical violence on women can be a major gateway for the entry of other major health related as well as lifestyle related difficulties. Violence is the act of forcing someone into doing something that they don't like as well as stopping them from doing something that they like. The activity that promotes violent act to women is considered as violence against women. The violence against women can cause various issues such as economic issue, social issue, morbidity issue, and psychological issue. The terrific situation of physical violence against women has to be resolved in time for the system to be able to function in the desired way. For the completion of this research, secondary data has been used in the analysis field so that the result of physical violence can be enlightened.

Keywords: Physical Violence, Violence, Women

\section{Background}

Introducing the topic; we understand violence as the act of forcing someone into doing something that they don't like as well as stopping them from doing something that they like. The activity that promotes violent act to women is considered as violence against women. The UN Declaration on the Elimination of Violence against Women (1993) states that "Violence against women is a manifestation of historically unequal power relations between men and women, which have led to domination over and discrimination against women by men and to the prevention of the full advancement of women, and that violence

${ }^{8} \mathrm{Mr}$. Paudel is associated with Research Nepal. Email: paudelbibek0@gmail.com 116 
against women is one of the crucial social mechanisms by which women are forced into a subordinate position compared to men (Shrestha, Kharel, Wasti, Aryal, \& KC, 2013).

Women are under violence throughout the world. Violence can be understood as the process in which one's basic rights to live freely is violated by another. The Convention for the Elimination of Discrimination against Women (CEDAW) and the UN article that prohibits torture have both brought VAWG out of the private and into public spheres globally and in doing so have recognized VAWG as an infringement of women's basic human rights (Hawkes, et al., 2013). Violence can be particularly defined as the process by which one's right is shrank to a smaller state than the average state which makes the people more vulnerable. Gender Based Violence (GBV), in its various forms, is endemic in communities around the world, cutting across class, race, age, religion and national boundaries. In general, women have been found to be more marginalized and vulnerable to both direct and indirect/structural violence in the extensive research that has been conducted on GBV globally (Warui, 2013).

Violence can be categorized mainly into two sub-parts as domestic violence and violence outside of house. "Domestic Violence" means any form of physical, mental, sexual and economic harm perpetrated by person to a person with whom he/she has a family relationship and this word also includes any act of reprimand or emotional harm (Shrestha, Kharel, Wasti, Aryal, \& KC, 2013). Violence can be of any types that include the blockage of one to do any activity as well as force someone to do any activity. Some of the violence of women can be enlisted as:

- Sexual abuse and exploitation: It is defined as any sexual act to women/girls proposing sex, teasing, sexual joking and presenting erotic behavior.

- Rape and marital rape: Rape is understood as any sexual activity that involves forceful intercourse and marital rape is considered as intercourse that takes place without consent of women partner.

- Child Marriage: The custom of marrying small children that are below the age legalized to marry by government.

- Polygamy: The custom of one man marrying many women as wife. 
- Physical violence: The activity of men to beat up their female partners.

- Dowry Related Violence: A custom of monetary exchange during marriage.

- Traditional Harmful Practices: The allegations of witchcraft are enlisted as traditional harmful practices.

- Chhaupadi Pratha: The tradition in which female has to remain separated during their menstrual cycle.

- Jari custom: The practice of marrying someone else's wife by paying money to him.

- Women/Girls trafficking: This is a criminal practice where a girl or a woman is sold for prostitution and slavery.

(FFW, 2006)

In the present world, women are found to be subjugated to violence. They are constantly under the suppression from men in most of the sectors. They have been under violence from the start of their life continued to their adulthood as well as old age. Around the world, at least one in every three women has been beaten, coerced into sex, or abused in some other way, one woman in four has been abused during pregnancy (Warui, 2013).

Gender discrimination exists in Nepalese society. In Nepalese society violence has been in practice since a long time as patriarchal system is the most persistent throughout the country. It initiates from the family and permeates at the community to the state level. Women are considered as inferior to men in almost every sector where women are compelled to bear violence because of their sex (Crime Investigation Department, 2011).

Even the culture of Hindu religion (ruling culture of present as well as past Nepal), is totally in favor of Patriarchal system which promotes violence against women in many sectors. The dominant Hindu religion and culture have popularized a belief that women should be dependent on men for income right from cradle to the grave. Men are considered as the sole breadwinners of families, and women are viewed as domestic and maternal only (FFW, 2006)News in Nepal is focused about the violence prevailing in Nepal. The increasing case of violence is a major issue that has to be noted in time. A Study of INSEC 
2013 shows that a total of 2348 victims have been documented by INSEC in regards to VAW. 178 total women and girls have been killed in VOW and 108 on domestic violence alone as in 2013. Data have shown that the women and children of Nepal are among the high-risk groups of crime and violence from a world overview. $6 \%$ of total crimes took place in Nepal were related to crimes against women and children i.e. 1468 out of 22632 crimes in 2069/70 (Ghimire \& Sharma, 2014). The key causes of violence are alcoholism, gambling, male dominance, dowry disputes, poverty and unemployment including mass illiteracy among women. The adverse consequences of crime/ violence on women's live are physical, mental torture and disintegration of family. The disadvantaged group, poor, single women, domestic workers, those working in hotels and restaurants, adolescents and youths, women whose husbands are in foreign employment are at great risk of violence both in private and public sphere (Crime Investigation Department, 2011).

\section{Objectives/ Methodology}

The main objective of this research is to enlighten about the consequences that might incur when a women or girl are subjugated to physical violence. For the completion of the research, secondary data will be used. All the secondary data will be considered for the analysis part of the research.

\section{Discussion}

\section{Legal Provisions}

For solving the issues of Gender based Violence, there are some legal provisions that helps to tackle issues related to violence against women in case of world:

- Universal Declaration of Human rights (UDHR), 1948: Universal Declaration of Human rights, 1948 in its preamble has clearly pronounced about the equality between men and women and assurance of fundamental rights as well as human rights for their social progress.

- International Covenant on Civil and Political Rights (ICCPR), 1996: It states that no distinction would be made to enjoy the rights enshrined in the present covenant.

- International Covenant on Economic, Social and Cultural Rights (ICESCR), 1996: 
It ensures the person's right to freely pursue their economic, social and cultural development.

- Convention on the elimination of all forms of discrimination against Women (CEDAW), 1979: This convention was enacted to address the rights of women i.e. physical, mental, sociological, economical, psychological and political rights.

- Convention against Torture and other Cruel, Inhuman or Degrading Treatment or Punishment, 1984: Includes the provision of defining torture and the ways to stop it i.e. rules and regulations against the person involved in torture.

- Convention on the Rights of the Child (CRC), 1989: This convention totally focuses on child rights from their birth to the time when they are independent.

- SAARC Convention on Preventing and combatting Trafficking in Women and Children for prostitution has emphasized that the evil of trafficking in women and children for the purpose of prostitution is incompatible with the dignity and honor of human beings and is a violation of basic human rights and recalling the relevant international legal instruments relating to prevention of trafficking in women and child. Other legal provisions are Convention for the Suppression of Trafficking in Persons and of the Exploitation of Prostitution of Others, 1949; Convention on the Elimination of all Forms of Discrimination against Women, 1979; International Covenant on Civil and Political Rights, 1966; and the Convention on the Rights of the Child, 1989.

Other legal provisions have also been made in case of gender related issues i.e. specially in case of Women's issues. Some of them are Domestic Violence (Offence and Punishment) Act, 2009 which ensures the protection of the victims of violence, shows them the pathway to justice, helps in retaining the compensation for the violence and giving punishment to the guilty persons, etc. and Domestic Violence Offence and regulation, 2010 that further enhances the provisions in previous act i.e. prompt health checkup and protection of victims of domestic violence (Crime Investigation Department, 2011). In the Case of Nepal, some legal reforms have been made in order to address domestic violence as; Interim Constitution of Nepal 2007 where some fundamental rights to people has been ensured as right to freedom, right to equality, right against untouchability and racial discrimination, right of women, right to property, right to social justice, right to children, 
etc. and also the muluki ain where the people who break the gender related rules will be duly punished with the imprisonment as well as fine in monetary values. The rights of women are included in Nepalese constitution 2072 under article of fundamental right.

\section{Review}

The history related to gender related violence can be traced back to our historical ages as Ram Charita Manasa states, "Drums and idiots, outcasts, beasts and women are fit only for beating". Similarly, there is saying that emphasize the discriminatory practice as" let it be late, but it should be son", "the birth of a son paves the way to heaven", "a daughter is born with doomed faith", "women are always happy shortsighted" (FFW, 2006). In Medieval Nepal 'Kirata and Lichhavi period', Violence was considered as sin and as such those who created violence in the society were given harsh punishment as "eye for eye, tooth for tooth and life for life". In Medieval period, the rulers of almost all kingdoms and principalities were Arya- Hindu. They governed the kingdom with Dharmasastra. Crimes and sins at those times were jumbled in a cluster and termed as Strihatya, Brahmahatya, Balhatya, Gou-hatya, Gotra hatya, Guruhatya, etc. and punishment for each case were made in their own cultural and religious terms. The time was equitable as even women who committed crime were equally liable of the punishment as shaven head and banishment from the country or state. The unification of Nepal led to creation of single governing body with their own religious and cultural practice for tackling against women violence. The specified and more strong form of governing practice was developed after the start of Code of Country (Muluki Ain) (1853 AD) which incorporated the punishment for all kinds of violent activities that might take place or that have been taking place in country (Pradhananga \& Shrestha, 2009).

Women's Development section was established under the Ministry of Local Development in 1980. After the restoration of multi-party democratic system in 1990, HMGN ratified the UN convention on Elimination of All forms of Discrimination against women (CEDAW). Ministry of women and social welfare was established after the Beijing conference in 1995. 6th plan started the upliftment process of women i.e. (1980-1984). Seventh plan (1985-1990) expanded the activities mentioned in $6^{\text {th }}$ plan. $8^{\text {th }}$ plan made commitment to create equal and meaningful participation of women in the development process. $9^{\text {th }}$ plan was progressive to incorporate the policy "Creation of a developed society on the 
basis of women's empowerment and gender equality through mainstreaming women's participation in each and every aspect of national development." $10^{\text {th }}$ plan had the primary objective to create an egalitarian society based on improving the rights of women by improving GDI by eliminating all forms of discrimination against women to get economic growth and poverty eradication. (FFW, 2006).

Violence to women takes place from the day one of their fertilization i.e. from the day from which the fertilization process takes place. After the fertilization, if people find out the fetus is a female then the family go for abortion. So, this clearly shows the existing condition of women and girls is vulnerable i.e. they will be under threat from the first day of their existence to the last day of their death. This severe situation has caused the productivity to decrease and the human capital to diminish in their status. Violence against women lowers economic productivity, drains resources from public services and employers, and reduces human capital formation (UN, 2006). So, any female that takes birth or are in the process of taking birth are abused and mistreated in many kinds which has formed as a life-cycle of women.

\section{FIGURE 1.1 THE LIFE CYCLE OF VIOLENCE AGAINST WOMEN}

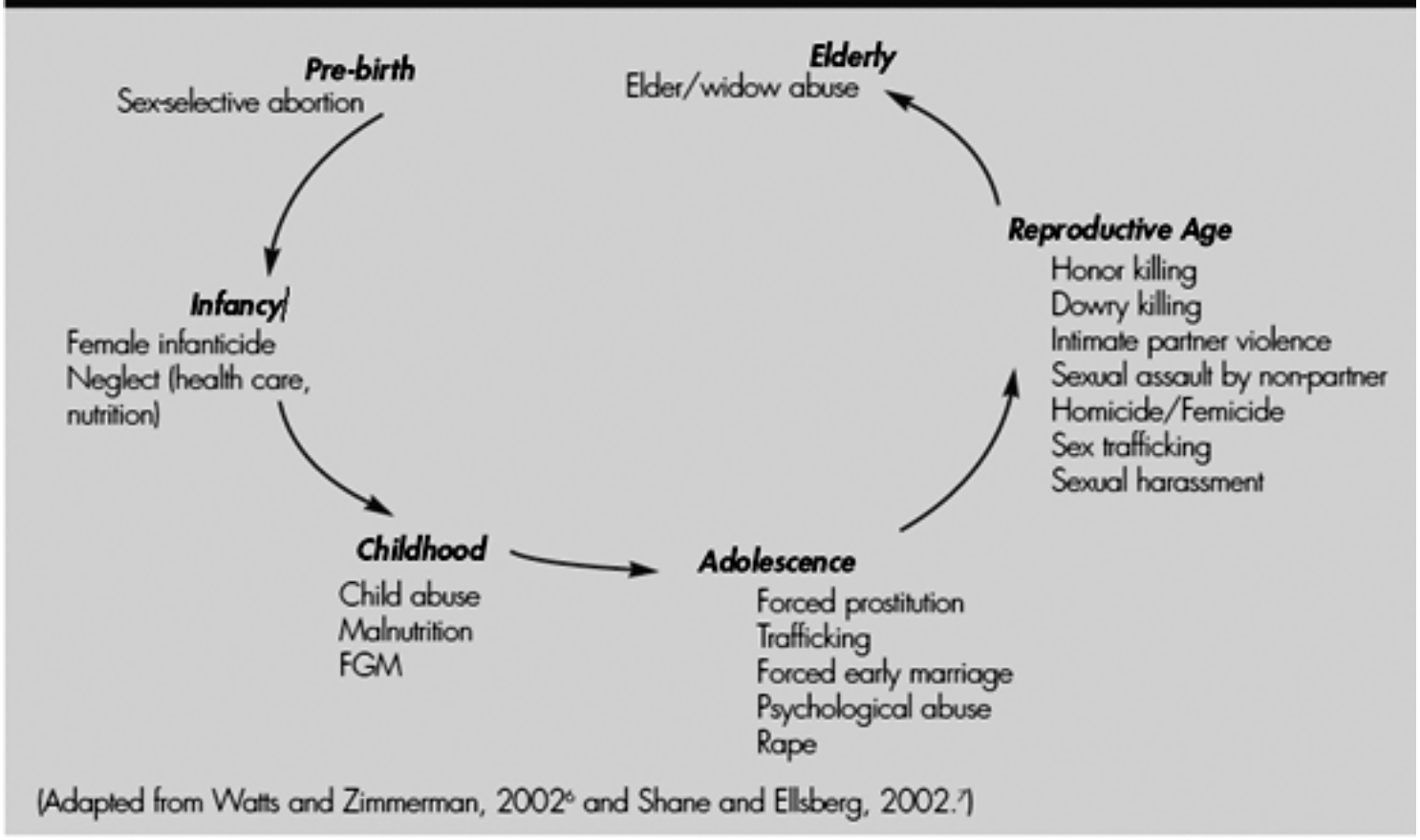


(Ellsberg \& Heise, 2005).

\section{Discussion}

\section{Health}

In case of Health, violence against women effects both the physical and mental status of women. In case of Health of women, the women might be traumatized as a result of physical violence. Other than the traumatization, they might develop fatal diseases as AIDS (Acquired Immune Deficiency Syndrome) that leads to the fatality of the female population.

A female who goes through physical violence can develop mental issues that are nonfatal but are very dangerous for their sound living of that female as well as their family. The over exposure to violence might lead to the person being disabled mentally as well as physically, might develop habits of alcoholism as well as drug use and so on. So, the violence against women not only decrease the productivity of the women, it also makes them 'disabled' in-terms of their well living in the society. 


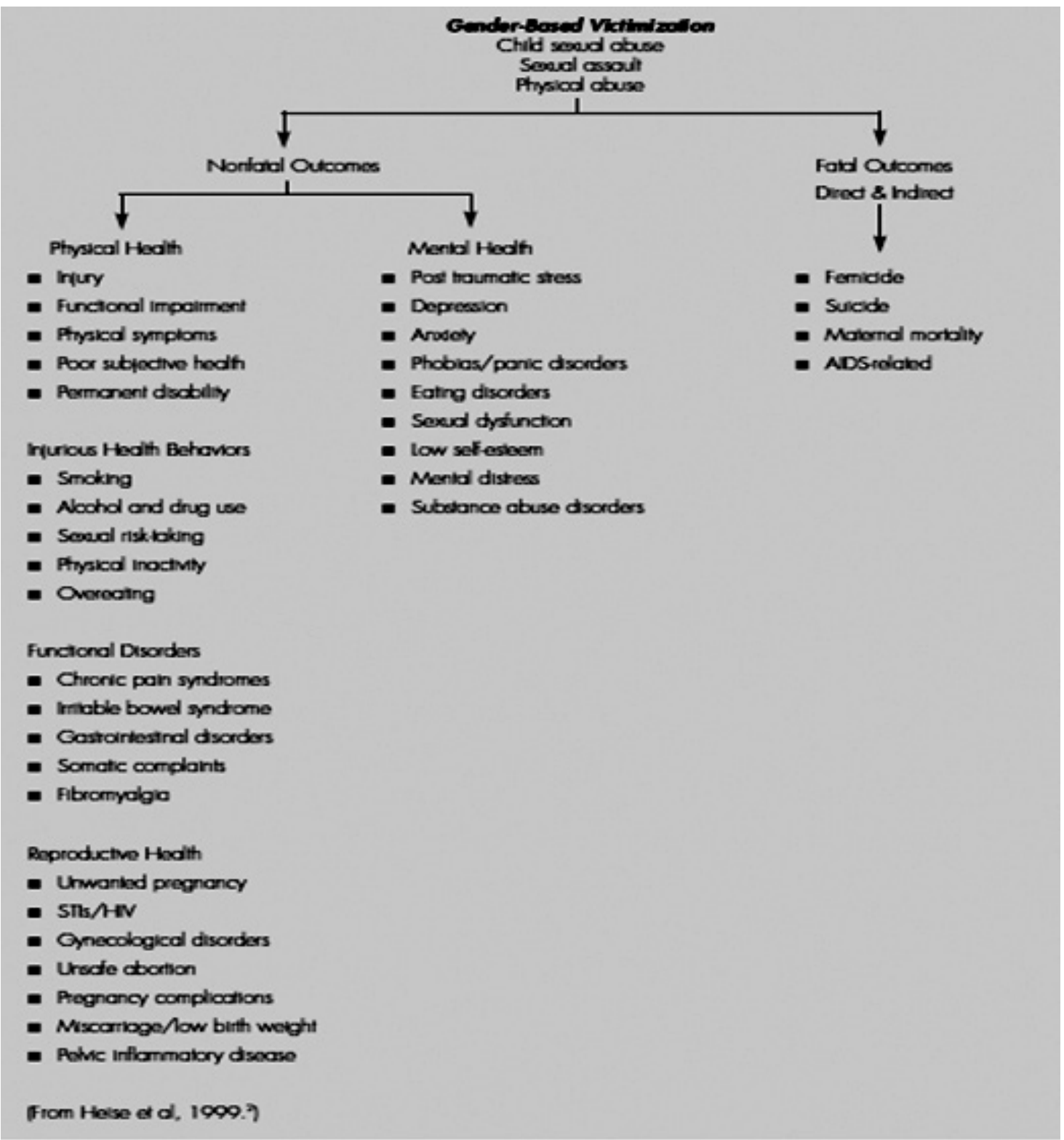

(Ellsberg \& Heise, 2005).

Mental Health

Violence can be a problematic situation in terms of mental health of a woman. One who bear the torture of violence is prone to have mental illness and are often found to be depressed. The severity of the depression is determined by the level of violence that they 
had gone through in their time where the level of violence is differentiated by the inhome violence i.e. by intimidate partner and out-home violence i.e. by other individuals. Women exposed to physical and psychological IPV had a higher incidence and severity of depressive and anxiety symptoms, PTSD (post-traumatic stress disorder), and thoughts of suicide than control women, with no differences between the two abused groups (PicoAlfonso, et al., 2006).

The violence can be long lasting as well as short timed impact on any individual. Specially the females; who are more emotionally advantageous than male counterparts; are more vulnerable in terms of psychological disorder after being a victim of a violence. The disorder can be a short as well as long term impact depending upon the case and the degree of emotional attribute that the individual possesses.

- Research in the United States has shown that battered women, as compared to women not living with violent men, are five times more likely to commit suicide and require psychiatric treatments.

- In one study in León, Nicaragua, after controlling for other factors, researchers found that abused women were six times more likely to report experiencing mental distress than non-abused women.

- The León, Nicaragua, study reported that children who had regularly witnessed their mothers being hit or humiliated, compared to other children, were at least five times more likely to experience serious emotional and behavioral difficulties.

(World Health Organization, 1997)

Physical Health

Like other health issues, a woman subjugated to gender based violence are more physically weakened and are vulnerable to any kinds of physical

- A study of 249 court records in Zimbabwe revealed that 59\% of homicides of women were committed by the intimate partner of the victim.

- Research in Cambodia found that 50\% of all women reporting abuse had sustained Injuries 
- In a three-year study of 1203 pregnant women in hospitals in Houston and Boston, United States, abuse during pregnancy was a significant risk factor for low birth weight, low maternal weight gain, infections and anemia.

- In one study of abused women in Bogotá, Colombia, 49\% reported that their children had also been beaten.

- In Thailand, researchers found that one in ten victims of rape had contracted a STD because of the attack.

- A United States study found that women who experienced childhood sexual abuse are nearly three times more likely than non-victimized youth to become pregnant before the age of 18 .

- In a study in Bombay, India, 20\% of all pregnancies of adolescent abortion seekers occurred because of forced sex, $10 \%$ from rape by a male domestic servant, $6 \%$ from incest, and $4 \%$ from other rapes.

- A major study in the United States found that having been the victim of childhood abuse or violent crime doubled a woman's likelihood of suffering from severe menstrual problems, a sexually transmitted disease, or a urinary tract infection; domestic violence tripled her likelihood.

(World Health Organization, 1997)

\section{Social Status}

When women are frequently subjugated to violence, the social status of the women deteriorates. Not just the status deteriorates, their capacity to develop also downfalls. Any external methodologies applied to raise the level of women and relieve them of their misery also becomes unsuccessful. Violence against women is likely to constrain poverty reduction efforts by reducing women's participation in productive employment, undermines efforts to improve women's access to education as violence and the fear of violence lower school enrolment for girls (Garcia-Moreno \& Watts, 2016)

As a result of violence, all the girls have to be constrained to a smaller circle where they can't express themselves nor can they participate in the expressive environment of the 
world (freedom). They will have to remain constrained in-terms of getting the knowledge and developing their lifestyle. Domestic violence has also been shown to affect the welfare and education of children in the family. (Garcia-Moreno \& Watts, 2016). One study in the United States showed that outpatient care for women with a history of sexual or physical assault cost two and a half times as much as care for other women, after controlling for other variables (World Health Organization, 1997)

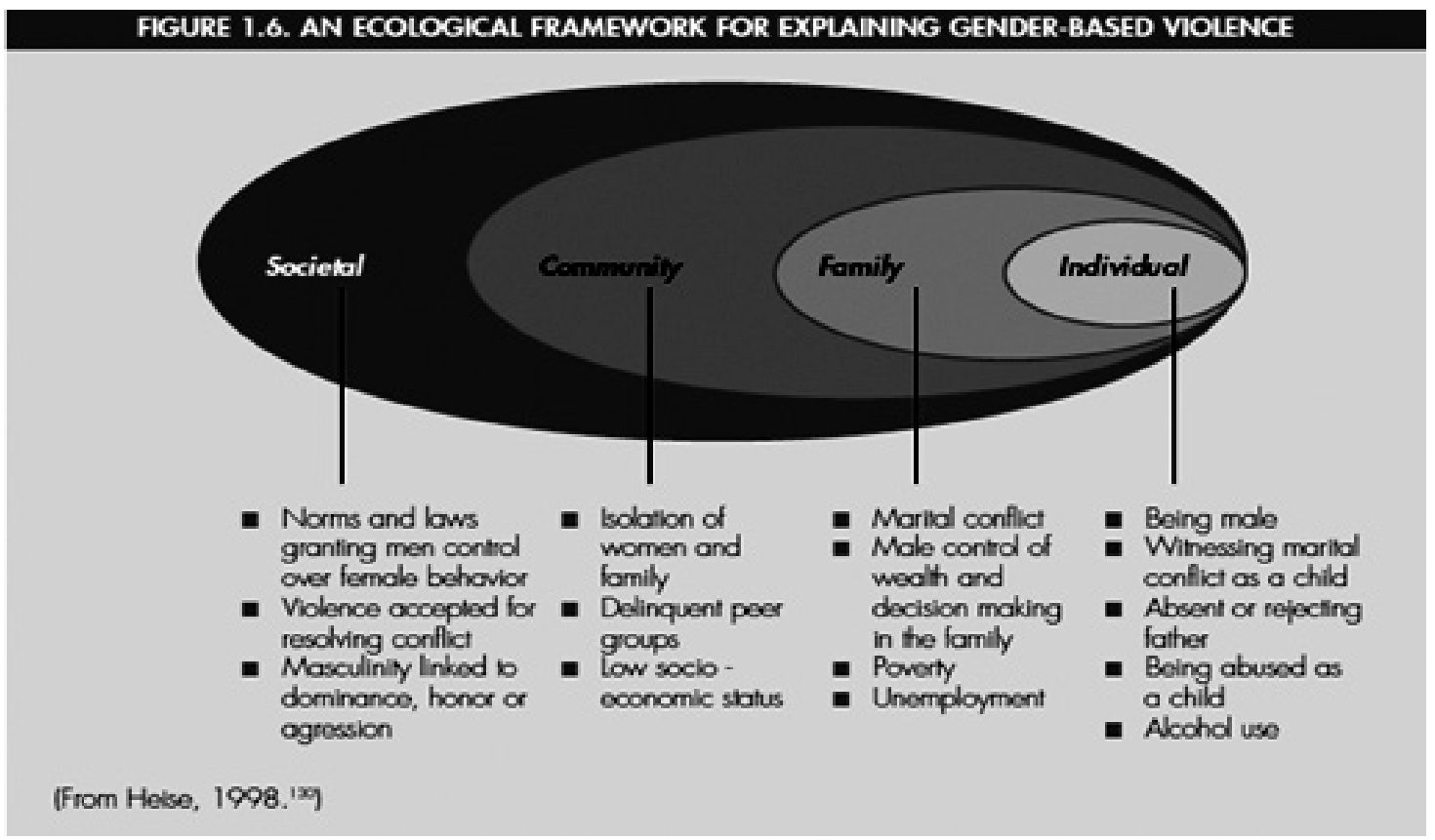

(Ellsberg \& Heise, 2005).

The violence against women takes place from the individual level to the societal level. Starting from the individual level, the violence takes its toll to the societal level through family and community level as shown in the figure above.

\section{Economic Status}

Talking about the economic status, the violence against women restrains involving themselves in any kinds of income generation activities. They will have to remain enclosed inside the four fences of a family and restrain themselves from any kinds of economic activities. With the violence against women increases, there is absolute possibility that the total productivity of the world decreases as the world constitute of $1 / 2$ of female population 
and if they can participate in income generation activities as well as any kinds of economic activities then serious problem might strike the world's economy at large. In Uganda, for example, the cost of domestic violence was estimated at 2.5 million United States dollars in 2007 and in 2002, Health Canada estimated that the direct medical costs of all forms of violence against women was 1.1 billion Canadian dollars (Garcia-Moreno \& Watts, 2016). One development strategy in Madras, India, nearly collapsed when women began dropping out because of the increased incidents of beatings from their husbands, after the women had joined the project (World Health Organization, 1997)

\section{Mortality}

Violence is sure a leader of increasing mortality and morbidity. When a woman is tortured, then her physical state deteriorates. One day of torture might cause physical illness but continuous torture can depart the soul from within. Other than the physical health deterioration, one who constantly suffers violence will go to a state where their mentality might be self-centric and might also go to the mental state of 'relieving mortal pain' where they might no longer wish to live their life. Violence is also an important cause of morbidity from multiple mental, physical, sexual and reproductive health outcomes, and it is also linked with known risk factors for poor health, such as alcohol and drug use, smoking and unsafe sex (Garcia-Moreno \& Watts, 2016). Media monitoring report conducted by ASMITA in 2014 revealed that the media overshadows the violence news against women.

\section{Conclusion}

We can conclude that the physical violence against women is life threatening of that women. Not just that women, it can be a devastating force that might destroy the whole nation. The attribute of the physical violence to be a non-fatal but mind depleting agent creates a condition in which they can no longer actively do their work and get the most efficient output from their work. The violence also takes its toll on the society thus leading to production of manpower who have the fear of violence as well as restrained capacity. The decreased will-power of female to live their normal life and the restrained capacity to develop might decrease the productivity of nation thus decreasing the GDP. Despite the fact that people have the idea on the possible impacts of physical violence against women, 
no any kinds of efforts have been made that directly tackles the problem as the problem itself is in hidden corner of life. No one freely likes to describe the violence against them. So, this situation is getting worse and is acting like a cancer which is growing and developing from within but is not seen to the world. Despite its hidden attribute, this is destroying and depleting the structure of society as well as mankind.

\section{References}

An update of Discriminatory Laws in Nepal and Their impact on Women. (2006).

Forum for women, Law and Development.

Crime Investigation Department, D. o. (2011). Baseline survey on violence against women and children of five project districts. Kathmandu: Business promotion Research and Communication Pvt. Ltd.

Ellsberg, M., \& Heise, L. (2005). Researchning violence against women. Geneva: World Health Organization.

Garcia-Moreno, C., \& Watts, C. (n.d.). Violence against women: an urgent public health priority. Genebra: World Health Organization.

Ghimire, K. J., \& Sharma, N. P. (2014). An overview on Crimes against Women and Children and measures for effective control:Nepali Experience. NJA Law Journal, 83-113.

Hawkes, S., Puri, M., Giri, R., Lama, B., Upreti, T., Khadka, S., . . SHakya, B. (2013). Tracking cases of gender-based violence in Nepal: Indic=vidual, Institutional, Legal and Policy analyses. CREHPA.

Koss, M. (1990). The women's mental health research agenda: Violence against women. American Psychologist, 374-380.

Pico-Alfonso, M., Garcia-Linares, I., Celda-Navarro, N., Blasco-Ros, C., Echeburua, E., \& Martinez, M. (2006). The impact of physical, psychological, and sexual intimate male partner violence on women's mental health: depressive symptoms, posttraumatic stress disorder, state anxiety, and suicide. Journal of Women's Health, 599-611. 
Pradhananga, R. B., \& Shrestha, P. (n.d.). Domestic violennce against women in Nepal: Concept, History and Existing Laws.

Shrestha, S., Kharel, Y., Wasti, P., Aryal, G., \& KC, A. (2013). VIolence against Women/ GIrls Assessing the situation of Nepal in 2013. Kathmandu: INSEC.

UN. (2006, October 9). Ending violence against women; from words to action: Study of secretary-general. United Nations.

Warui, M. N. (2013). Perceptions on Gender Based Violence By Male and Female REfugees in Dagahaley REfugee Camp, Northeastern. Nairobi: Institute of ANthropology, Gender and African studies in partial fulfillment of the requirements for the award of degree of master of arts in Gender and Development studies of the university of Nairobi.

World Health Organization. (1997). Violence against women: Health consequences. World Health Organization 